\title{
Percutaneous Coronary Intervention Versus Coronary Artery Bypass Graft in Left Main Revascularisation
}

\author{
An Expert Interview with Timir Kumar Paul \\ Cardiovascular Research, Quillen College of Medicine, East Tennessee State University, Johnson City, TN, USA
}

DOI: https://doi.org/10.17925/HI.2020.14.1.11

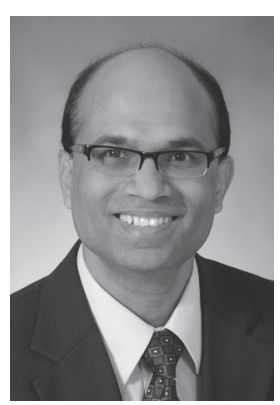

Timir Kumar Paul

Timir Paul, MD is an Associate Professor of Medicine at East Tennessee State University, TN, USA. He serves as Director of Interventional Cardiology and Associate Program Director of Cardiology Fellowship at Quillen College of Medicine. He is a full-time interventional cardiologist and performs coronary interventions via radial artery and complex coronary interventions with haemodynamic supports. He also performs endovascular interventions for peripheral arterial diseases and transcatheter aortic valve replacement procedures. His research interests include subclinical atherosclerosis, vein graft intervention, embolic protection devices, preventive cardiology, transcatheter aortic valve replacement, anticoagulation, antiplatelet and peripheral arterial diseases. Dr Paul has authored over 100 publications and published and presented more than 150 abstracts in both national and international scientific meetings, receiving "Best of the Best Abstracts Award" at the Society for Cardiovascular Angiography and Intervention, 2018. He collaborated and implemented two Institutional Review Board-approved retrospective and prospective multicentre national registries as a local principal investigator in collaboration with the University of Texas (UT) Southwestern. He is an invited speaker for several national scientific meetings, including Cardiovascular Revascularization Therapy, Society of Coronary Angiography and Intervention, Emory Practical Interventional Conference, Complex Cardiovascular Catheter Therapeutics and Cardiovascular Innovations. He currently serves on the editorial board for Cardiovascular Revascularization Medicine and PLOS ONE, has previously served as guest editor for PLOS ONE and has served on the editorial board for Cardiology Review Online from 2013-2016 and Heart International from 2018-present. He serves as reviewer for many prestigious cardiology journals including Catheterization Cardiovascular Interventions, Atherosclerosis and British Medical Journal. He serves as a reviewer for American Heart Association (AHA) grants and abstracts and other scientific meetings. Dr Paul received his MD degree from Dhaka Medical College, Bangladesh. He was awarded his MPH and PhD in Cardiovascular Epidemiology and Biostatistics from Tulane University, New Orleans, USA. He pursued a cardiovascular disease fellowship and an interventional cardiology fellowship at Ochsner Clinic, New Orleans and University of North Carolina-Chapel Hill, USA.

\section{Keywords}

Left main revascularisation, left main coronary artery, coronary artery bypass graft, coronary artery disease, percutaneous coronary intervention

Disclosure: Timir Kumar Paul has no financial or nonfinancial relationships or activities to declare in relation to this article.

Review Process: This article is an expert interview and, as such, has not undergone the journal's usual peer-review process.

Compliance with Ethics: This article is an expert interview and did not involve any studies with human or animal subjects performed by the author.

Authorship: The named author meets the International Committee of Medical Journal Editors (ICMJE) criteria

for authorship of this manuscript, takes responsibility for the integrity of the work as a whole, and has given final approval to the version to be published.

Access: This article is freely accessible at touchCARDIO.com (C) Touch Medical Media 2020.

Received: 10 February 2020

Accepted: 25 February 2020

Published Online: 12 March 2020

Citation: Heart International. 2020;14(1):11-2

Correspondence: Timir Kumar Paul

329 N State of Franklin Road, Johnson City,

TN, 37604 USA. E: pault@etsu.edu

Support: No funding was received in the publication of this article. eft main (LM) coronary artery disease is the atherosclerotic narrowing of the LM segment, and is often associated with involvement of ostial disease of the left anterior descending and left circumflex arteries, called distal LM disease. Significant LM disease is defined as $\geq 50 \%$ angiographically detected stenosis of the LM or angiographically $<50 \%$ stenosis with positive functional tests/haemodynamics. The management options for LM coronary artery disease have evolved over recent decades; previously, coronary artery bypass graft (CABG) surgery has predominately been the gold standard in treatment, but percutaneous coronary intervention (PCI) has evolved as an attractive alternative, due to its continuing advancements. ${ }^{1,2}$ Still, the choice of revascularisation has been a topic of extensive debate and there are various factors that need to be taken into account when considering these management options, including safety, durability, survival and the potential need for repeat revascularisation.

In this expert interview, we speak with Dr Timir Paul on the topic of LM revascularisation, pitting $\mathrm{CABG}$ against $\mathrm{PCl}$.

\section{Q. What is the background for surgical (coronary artery bypass graft) versus percutaneous revascularisation of left main coronary artery disease?}

The LM coronary artery supplies $>80 \%$ of the left ventricular myocardium; therefore, high-grade LM stenosis (>50\%) places a large myocardial territory at risk for ischaemia with higher risk of major adverse cardiac events. ${ }^{3.4}$ Medical therapy alone is inferior to CABG in patients with significant LM stenosis. ${ }^{5} \mathrm{~A}$ meta-analysis including eight trials demonstrated that coronary revascularisation in addition to medical therapy resulted in a $79 \%$ and $80 \%$ relative risk reduction in 5-year mortality with $\mathrm{CABG}$ and $\mathrm{PCl}$, respectively, compared with medical therapy alone. ${ }^{6}$ Balloon angioplasty alone or bare metal stents were associated with significant recoiling or in-stent restenosis and this drawback is largely overcome with drug-eluting stents (DES). 


\section{Q. What are the key differences between the two revascularisation options?}

CABG is a surgical option that needs either arterial grafts, namely left internal mammary artery or radial artery, and/or saphenous vein graft harvesting. $\mathrm{PCl}$ is a percutaneous endovascular intervention that involves angioplasty (balloon dilatation) or atherectomy and stenting.

\section{Q. What are the key positives and negatives of these revascularisation methods/ interventions?}

CABG offers the advantage of bypassing long segments of disease or diffuse disease and complete revascularisation. The other advantage of CABG is a more durable procedure with less repeat revascularisation. In contrast, higher rates of residual angina are seen in patients treated with $\mathrm{PCl}$ that contributes to higher rates of repeat revascularisation. In patients treated with $\mathrm{PCl}$, de novo lesions outside the stented segments can lead to recurrent myocardial infarction and the need for repeat revascularisation. PCl offers quicker recovery, lower early adverse cardiovascular events and possibly short-term reduced risk of stroke. CABG is associated with delayed recovery, longer length of stay in hospital and issues with healing and infection, in addition to higher costs.

\section{Q. In which cases would you recommend percutaneous coronary intervention, and in which would you recommend coronary artery bypass graft? Would you recommend one therapy over the other for the majority of cases?}

When dealing with revascularisation of the LM, we should calculate SYNTAX score (an angiographic grading as used in the Synergy Between Percutaneous Coronary Intervention with Taxus and Cardiac Surgery trial) and STS (Society of Thoracic Surgeon) score. ${ }^{7}$ The SYNTAX score will provide anatomic complexity of lesions, and the STS score will give operative mortality risk. The multidisciplinary heart team approach, including the general cardiologist, interventional cardiologist and cardiac surgeon, along with a detailed discussion with the patient and their family covering the advantages and disadvantages of both approaches, is the key for successful LM revascularisation.
The decision for PCl versus CABG in patients with LM disease is best made by the local heart team considering the clinical comorbidities, technical challenges, and the likelihood of safely achieving complete revascularisation with each procedure. I do not recommend one procedure over another, as the revascularisation strategy is individualised and would be made by the heart team, taking into consideration each patient's preferences after an informed discussion.

The 2018 European Society of Cardiology guidelines on myocardial revascularisation gave $\mathrm{LM} \mathrm{PCI}$ a class I recommendation (i.e., treatment is recommended) if the SYNTAX score is $<22$, class lla recommendation (i.e., treatment should be considered) for a SYNTAX score 23-32, and class III recommendation (i.e., treatment is not recommended) for SYNTAX scores $>33 .{ }^{2}$ In general, ostial or trunk LM stenosis, Iow SYNTAX score, high operative mortality risk (STS score $>5 \%$ ) or limited life expectancy favours PCl. Complex LM bifurcation lesions or high SYNTAX scores favour CABG. In cases of medication noncompliance or instances where the patient cannot afford the medication, then CABG is preferable. The operator's skill and experience should be considered in selecting PCl. Due to long-lasting arterial graft, younger patients with diabetes and reduced left ventricular function are likely to yield better long-term outcomes with CABG.

\section{Q. What do you see for the future of left main coronary artery revascularisation?}

A heart team approach with appropriate patient selection, careful assessment of LM lesions and meticulous procedural technique makes $\mathrm{PCl}$ a viable option for $\mathrm{LM}$ stenosis. ${ }^{1,2}$ Favourable outcomes of $\mathrm{LM}$ PCI with newer-generation DES may affect treatment decisions of CABG versus $\mathrm{PCl}$. Advances in stent design and technology (such as newer-generation $\mathrm{DES}$ ) and $\mathrm{PCl}$ techniques, especially image-guided (intravascular ultrasound or optical coherence tomography) intervention, have contributed to the improved safety and efficacy of PCl. The availability of mechanical circulatory support may also improve the safety and outcomes of $\mathrm{PCl}$ in LM intervention with reduced left ventricular ejection fraction. Further studies are needed to validate the current optimism for $\mathrm{PCl}$ as a valid alternative to CABG. More hybrid revascularisation, such as mini thoracotomy with left internal mammary graft to left anterior descending artery and $\mathrm{PCl}$ to other arteries when appropriate in a protected LM, can also be considered as an alternative. $\square$
1. Levine GN, Bates ER, Blankenship JC, et al. 2011 ACCF/AHA/ SCAI Guideline for Percutaneous Coronary Intervention: a report of the American College of Cardiology Foundation American Heart Association Task Force on Practice Guidelines and the Society for Cardiovascular Angiography and Interventions. Circulation. 2011;124:e574-651.

2. Neumann F-J, Sousa-Uva M, Ahlsson A, et al. 2018 ESC/EACTS Guidelines on myocardial revascularization. Eur Heart $\rfloor$ 2019:40:87-165.

3. Kalbfleisch $\mathrm{H}$, Hort W. Quantitative study on the size of coronary artery supplying areas postmortem. Am Heart 1977:94:183-8

4. Ragosta M, Dee S, Sarembock IJ, et al. Prevalence of unfavorable angiographic characteristics for percutaneous intervention in patients with unprotected left main coronary intery disease Cotheter Cardiovasc Interv 2006;68.357-62. artery disease. Catheter Cardiovasc interv. 2006,68.357-62. Yusuf S, Zucker D, Peduzzi P, et al. Effect of coronary artery bypass graft surgery on survival: overview of 10-year results Surgery Trialists Collaboration. Lancet. 1994;344:563-70.
6. Shah R, Morsy MS, Weiman DS, Vetrovec GW. Meta-analysis comparing coronary artery bypass grafting to drug-eluting stents and to medical therapy alone for left main coronary artery disease. Am J Cardiol. 2017;120:63-8.

7. Serruys PW, Morice M-C, Kappetein AP, et al. Percutaneous coronary intervention versus coronary-artery bypass grafting for severe coronary artery disease. N Eng/ I Med. 2009;360:961-72. 